\title{
QUE ANTIGA QUERELA ENTRE POESIA E FILOSOFIA?
}

\author{
Glenn W. Most ${ }^{* 1}$
}

\begin{abstract}
RESUMO: In a celebrated passage of Plato's Republic, Socrates speaks of "an ancient quarrel between poetry and philosophy" (Rep. X, 607b-c). But did such a quarrel ever really exist in pre-Socratic Greek culture? Examination of the evidence of Greek poetry and philosophy from the centuries preceding Socrates reveals, with a single exception, little or no trace of any such quarrel in either direction, philosophers attacking poets or poets attacking philosophers. The only poetic genre in which attacks upon philosophers were frequent was Old Comedy; Socrates himself was notoriously a prominent target. And all four passages that Socrates cites in support of his claim are best interpreted as deriving from Old Comedy. The paper considers how we can understand the ensuing likelihood that the quarrel to which Socrates refers had no existence outside of Old Comedy on the one hand and Plato's philosophy on the other.
\end{abstract}

PALAVRAS-CHAVE: Platão, Filosofia, Poesia, Comédia Antiga.

Meu título deriva de uma celebrada passagem na República de Platão, uma passagem que é citada regularmente em discussões acadêmicas sobre sua visão da poesia. Ela ocorre no livro X, próxima do final da segunda análise estendida da poesia nessa obra:

\begin{abstract}
Que seja esta a nossa defesa - agora que retornamos ao tópico da poesia -, que em vista de sua natureza, nós tivemos razão para bani-la da cidade anteriormente, pois nosso argumento nos compeliu a fazê-lo. Mas, caso sejamos acusados de certa rudeza e falta de sofisticação, também digamos à poesia que há uma antiga querela entre ela e a filosofia, que é evidenciada por expressões tais como a "cadela rosnando para seu dono", aquela que grunhe; "grande na eloqüência vazia dos tolos"; a "turba dos críticos excessivamente sábios"; e os "pensadores sutis" que são "todos indigentes"; e miríades de outros sinais dessa oposição deles (República X, 607bc) $)^{2}$.

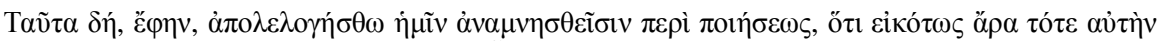

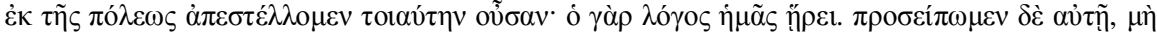

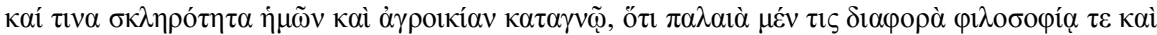

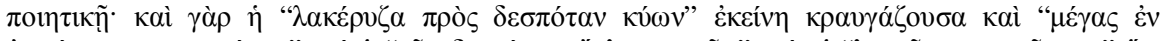

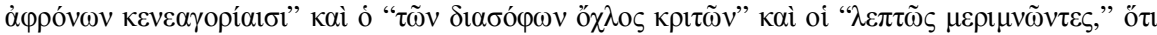

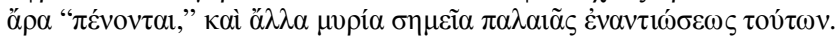

\footnotetext{
* Professor da Scuola Normale Superiore di Pisa e da University of Chicago.

${ }^{1}$ Gostaria de agradecer Pierre Destrée, F. G Hermann e a Editora Brill pela permissão de republicar este artigo, que foi originalmente publicado em Pierre Destrée e F. G. Hermann (eds.), Plato and the poets, Leiden, Brill (no prelo). Muito obrigado também a Susanne Gödde, Alan Griffiths, Maria Chiara Martinelli e Mario Telò, por seus conselhos oportunos, profundos e expertos à uma versão previamente escrita; e a Lowell Edmunds, Richard Hunter e Dirk Obbink, por sua estimulante discussão de uma apresentação oral em Komotini em setembro de 2009.

${ }^{2}$ Esta tradução, assim como todas as outras neste artigo, é retirada de Cooper, 1997; modifiquei a ela e ao texto grego para refletir meu entendimento das citações poéticas (veja-se abaixo), e adicionei uma tradução das palavras finais, que estranhamente estão ausentes lá [Nota do Tradutor: as citações feitas pelo autor são traduzidas a partir da tradução para o inglês apresentada por ele, a fim de respeitar suas opções].
} 
Essas palavras de Platão são familiares; no entanto, apesar - ou talvez por causa - de sua própria familiaridade, sob inspeção mais detida, elas se mostram cheias de perplexidades inesperadas. Qual o exato tipo de oposição entre poesia e filosofia denotado pelas vagas palavras diaphora e enantiôsis? As frases poéticas que Sócrates cita pretendem provar meramente a afirmação de que essa oposição existia, ou também a afirmação ulterior de que ela é antiga, e, se sim, como devemos entender essa qualidade de ser antiga? Ademais, embora Sócrates fale de uma querela entre dois concorrentes, podemos ter certeza que era uma disputa igualmente equilibrada, dado que todas as frases que ele cita são de poetas contra filósofos? Como devemos entender que o fato de que ele fala, não de um concurso entre escritores individuais, entre poetas e filósofos, mas sim entre dois modos de discurso, poesia e filosofia, dado que todas as citações parecem ser dirigidas contra pessoas singulares ou conjuntos vagos de pessoas? $\mathrm{E}$, acima de tudo, como devemos interpretar as frases específicas que ele cita - quem as escreveu, e que queriam dizer seus autores originais, e como elas agora funcionam no interior do presente contexto argumentativo em que Platão as inseriu?

Em certa medida, a maioria desses assuntos já foi discutida por vários outros estudiosos $^{3}$, embora evidentemente eu tenha a mínima esperança de que reconsiderá-los aqui mostre ter algum grau de utilidade. Mas, com essas questões, há uma outra, não menos fundamental, que não parecer ter sido adequadamente explorada de modo algum, ou mesmo reconhecida mais do que algumas vezes: se de fato, na realidade, havia ou não havia algum tipo de antiga querela entre filosofia e poesia do tipo que Platão descreve aqui.

Para limitar as possibilidades de mal-entendidos, deixe-me tentar ser mais preciso. Minha questão não é se havia ou não havia, no interior dos escritos filosóficos de Platão, uma disputa de longa data entre poesia e filosofia. Pois o consenso acadêmico é que de fato havia, e essa visão é manifestamente bem fundada ${ }^{4}$. Do inicial Íon através dos mais maduros Banquete, Fedro e República, até o tardio Leis - para mencionar apenas esses diálogos -, a querela do próprio Platão com os poetas é bem estabelecida, bem arraigada, persistente, recorrente, explícita e intensa. Assim, provavelmente ninguém contestará a afirmação de que a filosofia de Platão engajou-se sincronicamente em uma discordância sistemática com os poetas e a poesia, e que essa discordância durou diacronicamente durante toda a sua carreira.

Pela mesma razão, é obviamente impossível entender a frase de Sócrates - "uma antiga querela entre ela [i.e. a poesia] e a filosofia" - como referindo-se ao domínio da filosofia de Platão - não apenas porque fazer isso inevitavelmente destruiria a ficção histórica da República de Platão (na data dramática do diálogo, não é provável que Sócrates tenha conhecido muito acerca do desenvolvimento dos escritos de Platão, desde seu começo até o fim), mas também porque as palavras de Sócrates designam-se manifestamente para justificar sua presente depreciação da poesia - ou, no mínimo, para defletir possíveis críticas a ela - por referir-se a uma hostilidade conspícua e de longa data entre os dois discursos, a respeito da qual Platão pode presumir que seus leitores não apenas saibam que ela existe, mas também que ela se situa fora e é anterior à corrente discussão e que encontra agora, nessa discussão, apenas sua mais recente (e, talvez, mais perfeita) exemplificação. Dessa forma, parece certo que Platão pode apenas

\footnotetext{
${ }^{3}$ Vejam-se, por exemplo, Gould, 1990, pp. 4-69; Rosen, 1988, pp. 1-26; Nightingale, 1995, pp. 60-67; Kannicht, 1996, pp. 189-91, 218-19; Murray, 1996, pp. 14-19; Levin, 2001, pp. 127-67; Naddaff, 2002, pp. 122-25.

${ }^{4}$ Vejam-se também, por exemplo, além dos trabalhos listados na nota precedente, Murdoch, 1977; Ferrari, 1989; Asmis, 1992; Moss, 2007.
} 
querer dizer que Sócrates está afirmando que havia uma bem conhecida e bem estabelecida antiga querela entre a poesia e filosofia muito anterior à data ficcional desse diálogo.

Então, surge a questão: havia? Na literatura moderna, a frase "antiga querela entre poesia e filosofia" foi usada com tanta freqüência que se tornou bastante banal; por exemplo, ela figura proeminentemente no título não apenas de um livro recente acerca das visões de Platão sobre a poesia ${ }^{5}$, mas também de vários estudos dedicados a aspectos das relações entre a poesia e a filosofia gregas em geral ${ }^{6}$. Particularmente, seu uso em estudos desse último tipo sugere que pelo menos alguns estudiosos modernos assumem que uma tal querela realmente foi um traço da antiga cultura grega antes de Sócrates - em outras palavras, eles parecem considerar Platão uma testemunha confiável de uma tradição real de hostilidade entre poesia e filosofia que existia independentemente antes de Platão (e, com efeito, antes de Sócrates). Isso se dá porque eles examinaram o tema e descobriram que as palavras de Platão são um reflexo acurado dela ou porque eles simplesmente adotaram sua autoridade sem questioná-la? Talvez valha a pena reexaminar a questão para ver precisamente quais poderiam ser os indícios de tal querela. Afinal, já em 1902, em seu comentário a essa passagem, Adam (1965, vol. 2. p. 417) notou que "há poucos vestígios dessa 'antiga contenda' nos fragmentos existentes do início da poesia grega". E, em tempos recentes, as vozes daqueles que, de um modo ou de outro, puseram em dúvida a própria existência de uma tal querela se multiplicaram: assim, Brock (1990, p. 40) argumenta que "a 'antiga querela entre filosofia e poesia' é para Platão essencialmente uma questão do ataque da comédia à poesia"; Nightingale (1995, p. 60) afirma que "a sugestão de Platão de que há uma 'antiga querela' entre esses dois gêneros não deveria ser interpretada como verdadeira reportagem histórica; antes, ela é parte de uma ousada estratégia retórica concebida para definir a filosofia e investi-la de um status semi-intemporal"; e Murray (1996, p. 231) sugere que Platão estava "ansioso para estabelecer a antiguidade da querela entre filosofia e poesia, mas suspeita-se de que ela era em grande medida sua própria criação"7 . Portanto, reconsideremos os indícios de uma tal querela.

Como bem se sabe, tanto na cultura quanto no casamento, qualquer boa querela precisa de dois lados. Comecemos, portanto, com um dos lados, a filosofia atacando a poesia: pondo de lado no momento a diferença entre expoentes individuais dos dois discursos e os discursos eles mesmos, perguntemos qual é o indício de filósofos criticando poetas antes de Sócrates. Xenófanes, como tem sido notado com frequiência nas discussões da "querela" 8 de Platão, explicitamente polemiza contra a representação dos deuses que se pode encontrar em Homero e Hesíodo (21 B 10-12 D-K) e também se opõe ao costume simposiástico de cantar canções sobre guerras de Titãs, Gigantes e Centauros $(\mathrm{B} 1)^{9}$. E a influência da crítica de Xenófanes à teologia épica sobre o criticismo do próprio Platão ao retrato dos deuses pelos poetas, no livro 2 da República, é manifesta. Assim, é tentador pensar em Xenófanes como um dos críticos filosóficos da poesia em quem Platão está pensando. Mas, mesmo que não seja improvável que Platão tenha ele mesmo entendido Xenófanes dessa maneira, é válido lembrar que, do

\footnotetext{
${ }^{5}$ Levin, 2001.

${ }^{6}$ E.g. Rosen, 1988; Gould, 1990; Kannicht, 1996.

${ }^{7}$ Cf. também Schlesier, 2006, que examina a questão relacionada de como devemos entender a afirmação de Platão de que a doutrina da inspiração poética era antiga (veja-se abaixo).

${ }^{8}$ E.g., Adam, 1965, vol. 2. p. 417; Nightingale, 1995, p. 64; Murray, 1996, 230.

${ }^{9}$ Não é claro precisamente qual tipo de costume Xenófanes tem em mente; certamente, tópicos como esses parecem estranhos à maior parte daquilo que pensamos saber sobre os simpósios gregos arcaicos. Será que essa passagem fornece indício da execução da Teogonia de Hesíodo em tais simpósios?
} 
nosso ponto de vista, é fácil reconhecer que Xenófanes - que escreve suas composições em versos do mesmo metro que os poetas que ele critica e que os apresenta, até onde posso dizer, nos mesmos tipos de récitas rapsódicas públicas que aquelas em que a poesia épica era executada - representa não tanto um ataque à poesia vindo do exterior, de um discurso externo e heterônimo como a filosofia, mas sim vindo do interior, do discurso da própria poesia; talvez como Hesíodo (Teog. 26-28), e certamente como Sólon (fr. 29 West), Píndaro (e.g. Neméias 7.20-24) e tantos outros versejadores arcaicos, ele é em certo sentido apenas mais um poeta a criticar outros poetas por eles não contarem o que é aquilo que ele chama verdade (mas que se resume, no final, à versão particular da tradição que, em determinadas circunstâncias, seja qual for a razão, ele por acaso prefere). Ademais, se Xenófanes fosse realmente oposto à poesia por princípio, por que é que ele escolheu fazer uso exclusivamente dela em todos os seus escritos? Então, seja qual for o modo como Platão tenha entendido Xenófanes, e estivesse ele pensando nele ou não, é muito pouco provável que Xenófanes tenha se entendido como um filósofo criticando poetas - não apenas no sentido trivial de que, no tempo em que ele escrevia, a palavra "filósofo" ainda não tinha sido inventada, mas também num sentido mais amplo e mais interessante de que o papel de Xenófanes como um rapsodo polêmico é característico das dimensões da poesia grega arcaica como uma instituição social cujas relações com a filosofia, como ela mais tarde veio a ser constituída, são complexas e indiretas ${ }^{10}$.

Qual, depois de Heráclito, o único filósofo pré-socrático que é regularmente citado em conexão com essa passagem platônica ${ }^{11}$ ? Heráclito também, com certeza, ataca Homero, Hesíodo e Arquíloco por nome (22 A 22, B 40, 42, 56, 57, 106 D-K) -, porém ele não ataca apenas esses poetas, mas também outras figuras, como Pitágoras, Hecateu e Xenófanes: com efeito, ele o faz exatamente num dos aforismos em que ele também critica Hesíodo (B 40). Dos alvos de Heráclito, Xenófanes escreveu poesia, na qual inter alia ele atacou outros poetas; Hecateu escreveu em prosa; Pitágoras provavelmente não escreveu absolutamente nada e as obras atribuídas a ele mais tarde eram em prosa. Portanto, parece haver pouca razão para pensar que Heráclito fosse particularmente oposto à poesia, ou estivesse atacando Homero, Hesíodo e Arquíloco porque eles eram poetas. Na verdade, suas críticas aos poetas parecem ser coerentes com seus ataques a todas e quaisquer figuras no âmbito da cultura grega que reclamaram para si a autoridade de sábio, em qualquer domínio, mas que não viveram de acordo com os altos padrões do próprio Heráclito - em política, por exemplo, os Efésios (B 121), e nos mistérios e em outras práticas religiosas, várias figuras e procedimentos rituais (e.g., B 5, 14, 15 D-K). Assim, Heráclito também parece não fornecer forte indício independente de uma tal querela.

Mas, fora Xenófanes e Heráclito, não há outro filósofo pré-socrático plausível que possa significativamente sustentar o lado dos filósofos na antiga querela a que Sócrates se refere ${ }^{12}$. Assim, os indícios de uma tradição de filósofos querelando com os poetas são, se não completamente inexistentes, muito escassos, na melhor das hipóteses.

Quê, então, a respeito da parte dos poetas na querela? Adam (1965, vol. 2. 417)

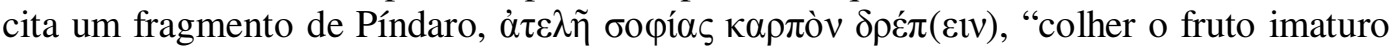
da sabedoria" (fr. 209 Sn.-M.); mas, mesmo que tanto Estobeu (ecl. 2.1.21, 2.7 W.-H.)

\footnotetext{
${ }^{10}$ Sem dúvida, pode-se dizer que a filosofia grega como um todo surgiu, em última instância, de tais dimensões da poesia grega arcaica. Mas isso é uma outra história, que eu discuti alhures: Most, 1999.

${ }^{11}$ E.g., Adam, 1965, vol. 2, p. 417; Nightingale, 1995, p. 64; Murray, 1996, p. 230.

12 Adam (1965, vol. 2, p. 417) menciona ainda Empédocles, mas não é claro o que ele tem em mente. Demócrito também discutiu poesia, mas não polemicamente, pelo menos nos fragmentos sobreviventes.
} 
quanto a vida bizantina de Píndaro (vit. Pind. Ambr. P. 4.6 Dr.), que transmite o texto, citem essas palavras como tendo sido escritas por Píndaro contra aqueles que eles identificam como hoi physiologountes, "os filósofos naturais", é certo que o próprio Píndaro não poderia ter aplicado e mesmo ouvido essa terminologia muito posterior (ela não é atestada antes do $4^{\circ}$ século a.C.), de modo que não podemos saber com certeza quem ele tinha em mente e devemos tratar essa identificação com cautela como uma possível, mas certamente anacrônica, interpretação acadêmica ${ }^{13}$.

Todavia (com uma única exceção genérica, à qual retornarei em breve), é ainda mais difícil encontrar indícios de qualquer outro poeta pré-socrático querelando com os filósofos do que de filósofos pré-socráticos querelando com os poetas. O próprio Sócrates cita quatro fragmentos poéticos como indício de poetas atacando a filosofia ${ }^{14}$ o fato de que ele cite apenas esse tipo de texto, e não aqueles em que filósofos atacam poetas, sem dúvida não se deve a que ele considere que este último tipo seja autoevidente (ou, alternativamente, não-existente), mas antes ao fato de que, no momento em que ele fala como um filósofo atacando poetas, ele então quer especialmente citar poetas atacando filósofos, a fim de criar a impressão de um tipo de justiça rígida - a filosofia, por assim dizer - está retomando o que é seu. As quatro citações são todas anônimas, não atribuídas nem a um autor, nem a uma obra, nem sequer a um gênero; os autores das passagens, até onde sei, não são identificados nem pelos escólios a essa passagem nem por nenhum comentário neoplatônico, e elas não parecem ter sido citadas por nenhum outro autor grego, seja independentemente ou, pelo menos, a partir dessa passagem; elas são desprovidas tanto de contexto local quanto mais amplo, e são de interpretação e análise métrica altamente incertas; até mesmo o exato limite das citações é incerto (não podemos ter certeza de que os excertos de Platão refletem sua estrutura métrica), e elas não estão acima da suspeita de serem textualmente corrompidas. No entanto, examinemo-las com os únicos instrumentos disponíveis neste caso - a análise interna de sua linguagem e seu metro - a fim vermos que luz eles podem lançar sobre essa querela.

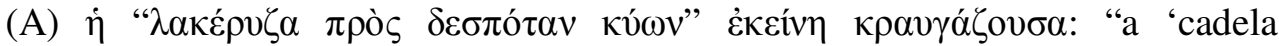
rosnando para seu dono', aquela que grunhe". O artigo definido provavelmente faz parte da citação, tanto aqui quanto em (C) e (D), mas tem, entretanto, uma função dêitica, apontando para uma formulação bem conhecida (nós o interpretamos como tó um citacional que assimilou o gênero do seu substantivo); o particípio kraugazousa é freqüentemente tomado como pertencente à citação também, mas, dado que a palavra ocorre apenas em autores de prosa e é sinônimo de lakeruza, parece muito mais provável ser uma glosa interpretativa, juntamente com o pronome ekeinê, com a qual Sócrates pretendia explicar o sentido da incomum palavra lakeruza. Se devemos delimitar a citação dessa maneira, então o metro resultante é uu-u--u-u-, que pode ser tentadoramente analisado como acephalous aristophaneus + jambo; alternativamente, e mais provavelmente, podemos supor que Platão não citou a passagem completamente e

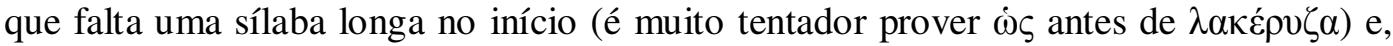
nesse caso, podemos tentadoramente sugerir o bem mais comum aristophaneus + jambo (completo $)^{15}$. Combinações muito parecidas ocorrem especialmente no drama grego,

\footnotetext{
${ }^{13}$ Os estudiosos freqüentemente consideram que Píndaro foi um inimigo da investigação racional da natureza; para dúvidas acerca dessa visão, veja-se Most, 2000.

${ }^{14}$ As citações são tomadas como fragmentos de poesia lírica e são editadas como frag. adesp. 987 em Page (1962, p. 524) (na terceira citação, $\tau \tilde{\omega} v$ é omitido erroneamente); em seu aparato, Page sugere que as duas últimas poderiam derivar, em vez disso, de um poeta trágico ou cômico. Até onde posso dizer, elas estão ausentes das edições padrões dos fragmentos de tragédia e comédia gregas.

${ }^{15}$ Neste último caso, uma análise alternativa, mas menos satisfatória, seria dochmius + hypodochmius.
} 
tanto em tragédia quanto em comédia (sendo o aristophaneus particularmente associado a Aristófanes) ${ }^{16}$. O cachorro que late para seu dono sugere uma combinação de insubordinação e estupidez: o cachorro propriamente treinado e inteligente late para estranhos e inimigos, não para seu próprio dono, e por essa mesma razão um tal cachorro é tomado como o modelo do guardião filosófico em Rep. II, 376b. Evidentemente, não é verossímil que essas palavras devam ser entendidas como sendo realmente apenas a respeito de cachorros: presumivelmente, cachorros são usados aqui metaforicamente e, dado que cachorros são comumente (embora não sempre) um símbolo do despudor valorizado negativamente na cultura grega, e que esse cachorro é uma fêmea, e que o cachorro mencionado aqui está fazendo algo que cachorros não devem fazer, pode haver pouca dúvida de que esse cachorro está sendo usado aqui para repreender alguém. Quem e por quê? Um indivíduo apenas ou um grupo? No contexto do discurso de Sócrates, poderíamos ser levados a pensar em algum filósofo em particular que atacou os deuses sendo comparado a uma cadela que late para seu dono ${ }^{17}$; porém, na ausência de qualquer contexto que seja, não é possível excluir absolutamente algum tipo de insubordinação estúpida. A imagem doméstica, vulgar mesmo, sugere a poesia jâmbica ou a lírica cantada na Comédia Antiga; o metro sugere fortemente a última (e o adjetivo é encontrado em Aristófanes, Aves 609) ${ }^{18}$.

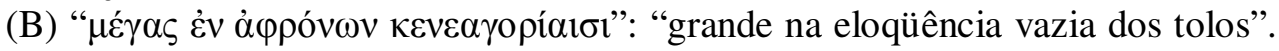
A primeira sílaba de aphronôn poderia ser longa ou breve, dependendo se muda + líquida aqui causa o alongamento por posição ou não ${ }^{19}$. Se nós assumirmos que sim, então o metro é uuu-u-uu-uu-u, que pode ser analisado como troqueu + hemíepes feminino $^{20}$; essa é uma combinação encontrada em três canções em Aristófanes ${ }^{21}$. É claro que as palavras descrevem algum homem que é poderoso entre os discursos vazios dos tolos, mas é menos claro justamente quem é o alvo. Caso se esteja afirmando que o homem é realmente poderoso, de modo que ele se destaca em meio (en) aos discursos dos tolos, então eles estão sendo atacados e ele está sendo louvado; caso se esteja afirmando que o homem é poderoso apenas a partir do ponto de vista dos tolos, de modo que é dentro (en) dos seus discursos apenas que ele é poderoso, então tanto ele quanto eles estão sendo atacados. Sócrates presumivelmente se inclina para esta última alternativa, mas, na ausência de qualquer contexto, não podemos excluir o primeiro caso. São os tolos membros de algum grupo em particular? Se sim, então nós poderíamos ter aqui um ataque a uma escola ou seita filosófica, e.g. "(Anaxágoras, ele mesmo um tolo realmente, e) grande (apenas) nos discursos vazios dos tolos (anaxagoreanos)". Ou os tolos são todas as pessoas, ou todos os membros de uma comunidade maior? Nesse caso, o que estaria em questão seria o prestígio justificado ou injustificado de uma única pessoa entre os tolos em geral. O conteúdo, fragmentário e

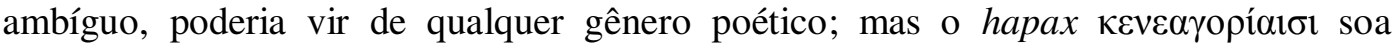

\footnotetext{
${ }^{16}$ Veja-se Parker (1997, pp. 82-84) sobre o uso de Aristófanes do aristophaneus.

${ }^{17}$ Em Leis, XII 967c-d, o Ateniense diz que alguns poetas (presumivelmente os poetas cômicos, em particular) acusaram certos

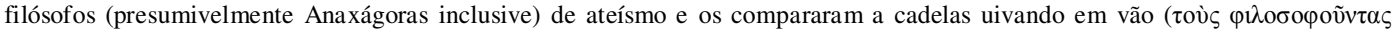

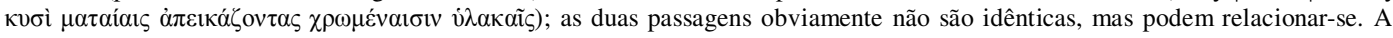
polêmica imagem do cachorro reaparece em ataques poéticos a filósofos posteriores: cf. e.g. Timon de Flio, Suppl. Hell. fr. 825, 832.2; isso pode ser motivado pela associação entre Cínicos e cachorros, pelas tradições poéticas a que Platão se refere, ou talvez mesmo pelas próprias passagens em Platão.

${ }^{18} \mathrm{Em}$ todos os demais lugares, o adjetivo é sempre aplicado a corvos nunca a cachorros: um malapropismo cômico?

${ }^{19} \mathrm{Tal}$ alongamento é raro na comédia, mas ocorre algumas vezes, especialmente quando um grau de seriedade intencionalmente reminiscente da tragédia ou da lírica elevada é almejado; cf. Parker, 1997, pp. 92-93.

${ }^{20}$ Uma análise alternativa, e mais difícil, seria crético + enopliano. Se tomamos a primeira sílaba de aphronôn como breve, não fica de modo algum claro como as palavras deveriam ser analisadas metricamente.

${ }^{21}$ Duas são monodias, uma é uma paródia de Eurípides. Veja-se Parker (1997, p. 39) para referências.
} 


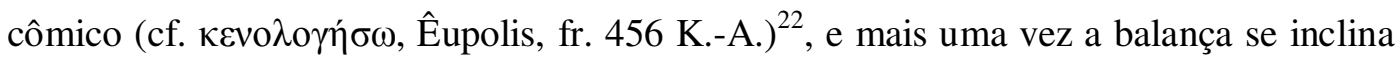
para uma canção da Comédia Antiga, talvez uma paródia ou uma alusão a um gênero sério.

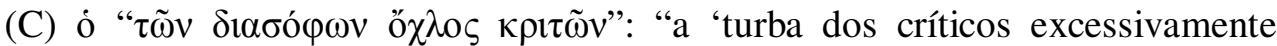
sábios"”. Essa citação apresenta várias dificuldades textuais ${ }^{23}$. A decisão mais fácil diz respeito ao artigo definido, que provavelmente deve ser excluído como dêitico tanto

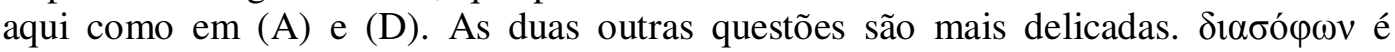
transmitido por dois do três principais manuscritos, ao passo que o terceiro lê $\delta$ í

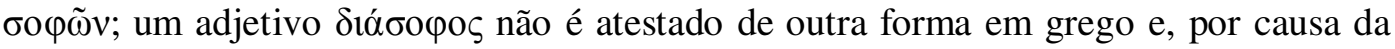
raridade de $\delta i \alpha$ - como prefixo com adjetivos, a lição se torna suspeita (Herwerden

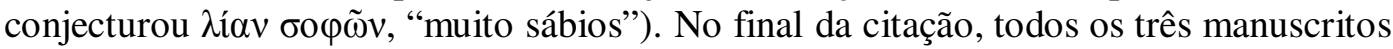
lêem $\kappa \rho \alpha \tau \tilde{\omega} v$, o particípio presente de $\kappa \rho \alpha \tau \varepsilon ́ \omega$ (“dominando, prevalecendo”); mas o particípio pendente em tal citação pareceu estranho para muitos estudiosos, que ou providenciaram um objeto para ele interpretando a lição do manuscrito como $\Delta$ ía... $\kappa \rho \alpha \tau \tilde{\omega} v$ ("prevalecendo sobre Zeus"; mas essa ordem de palavras parece impossível), ou

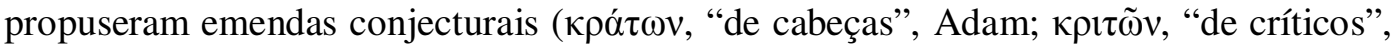

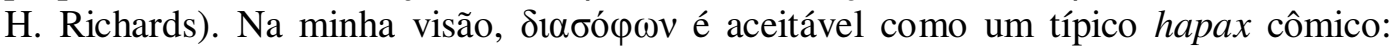
uma forma do verbo correspondente, $\delta \iota \alpha \sigma o \varphi i ́ \zeta \eta \tau \alpha l$, é atestada em Aristófanes (Aves 1619), e pode-se interpretar que o prefixo do adjetivo tenha uma função intensiva assim como no verbo ${ }^{24}$. Que, então, a respeito da última palavra? Se sua primeira sílaba é breve, então a citação pode ser metricamente analisada: -uuu-u-u-, i.e. dois jambos; mas, se aquela sílaba é longa, então o esquema resultante é: -uuu-u---, e não é de modo algum claro como isso deveria ser entendido metricamente - com efeito, essa talvez seja uma razão pela qual Adam (1965, vol. 2, p. 418) se sente impelido a combinar sua

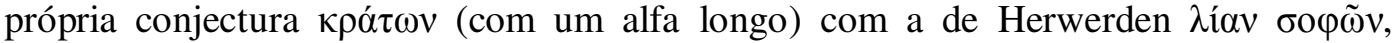

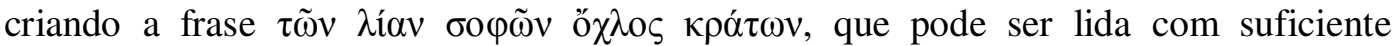
facilidade como lekythion + espondeu, mas às custas de uma dupla intervenção num texto completamente desprovido de qualquer salvaguarda contextual. Apesar de tudo, me parece mais prudente reter a primeira sílaba breve na última palavra da citação ler,

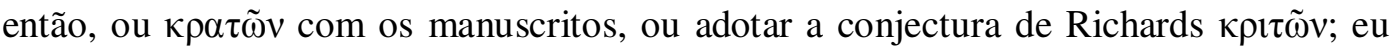
imprimi a última, com certa hesitação, baseado em que parece consideravelmente mais provável que as palavras citadas formariam uma unidade semântica completa, de modo que nós esperaríamos, não um particípio pendente, mas antes um substantivo genitivo

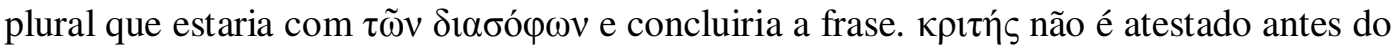
$5^{\circ}$ século com o sentido específico de "crítico literário", mas o termo é usado regularmente nesse século, especialmente na comédia ática, para referir-se aos juízes das competições dos festivais dramáticos ${ }^{25}$, e tal sentido seria totalmente apropriado aqui. Se essa análise é aceita, então a interpretação métrica como dois jambos deixa em aberto, em princípio, que eles poderiam vir da poesia jâmbica; mas um trímetro jâmbico arcaico se faz muitíssimo improvável pela falta de uma cesura pentemímera ou heptemímera. Por isso uma fonte dramática é muito mais provável; mas, se é assim, lírica recitativa ou cantada, cômica ou trágica? A ausência da cesura típica da tragédia significa que podemos tentativamente identificar a linha como sendo jambos líricos cantados ou, com maior probabilidade, dois metros de um trímetro jâmbico recitativo

\footnotetext{
${ }^{22}$ E cf., para paralelos posteriores num contexto similar, Tímon de Flio, Suppl. Hell. fr. 794 e 822. 2, especialmente.

${ }^{23}$ Minha análise dos problemas textuais se baseia na informação fornecida em Slings, 2003, p. 388.

${ }^{24}$ Wilamowitz sugeriu que o prefixo $\delta 1 \alpha$ - era o equivalente ático de Platão para o prefixo intensificador comum $\zeta \alpha-$ veja-se Slings, 2003, p. 388

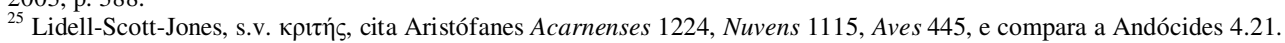


cômico; o termo levemente caricato $\delta 1 \alpha \sigma o ́ \varphi \omega v$ também aponta mais para a comédia do que para a tragédia (a palavra ő $\chi \lambda o \varsigma$ não fornece um critério de distinção, uma vez que é encontrada tanto em textos trágicos quanto cômicos ${ }^{26}$. Um outro elemento de prova sugestivo de que essa citação deriva de uma fonte cômica pode ser encontrado no fato de que a formulação, "a turba dos críticos excessivamente sábios", parece encontrar paralelo próximo num fragmento de um trímetro recitativo da Comédia Antiga, Cratino

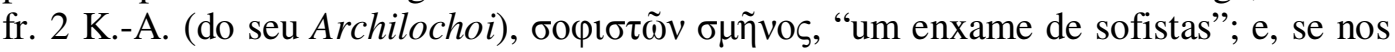
escolhermos adotar o $\kappa \rho \iota \tilde{\omega} v$ de Richards, isso forneceria um apoio adicional (admitidamente conjectural e circular) para um atribuição à Comédia Antiga.

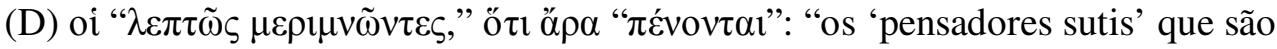
"todos indigentes"”. Finalmente, uma citação fácil, pelo menos relativamente. Colocando de lado o artigo definido dêitico como em (A) e (C), e reconhecendo nas palavras ő $\tau$ ä $\rho \alpha$ uma formulação de ligação que conecta dentro de uma única estrutura sintática duas partes de uma oração poética que não eram originalmente contíguos, ficamos com a seguinte estrutura métrica: --u- $\mathbf{u}$...---, que é facilmente interpretável como duas partes de um trímetro jâmbico recitativo, quer de poesia jâmbica, quer de tragédia ou comédia. Se o início de $\pi \varepsilon ́ v o v \tau \alpha$ lindasse diretamente com o fim de $\lambda \varepsilon \pi \tau \tilde{\omega} \varsigma$ $\mu \varepsilon \rho \mu \nu \tilde{\omega} \nu \tau \varepsilon \varsigma$, o resultado seria quase um trímetro jâmbico, mas a inserção das palavras de ligação ő $\tau$ ö $\rho \alpha$ torna extremamente improvável que as duas frases fossem imediatamente contiguas; presumivelmente, $\pi \varepsilon \dot{v} v 0 v \tau \alpha \iota$ ocorria na linha exatamente antes ou exatamente depois de $\lambda \varepsilon \pi \tau \tilde{\omega} \varsigma \mu \varepsilon \rho \mu \nu \tilde{\omega} \nu \tau \varepsilon \varsigma$. As palavras descrevem pessoas que, por todas as suas sutis cogitações, não conseguem tornar-se ricas, mas têm ainda de trabalhar duro por um sustento escasso. Embora nada no metro ou na linguagem dessas palavras forneça um critério para preferir-se uma fonte jâmbica, trágica ou cômica (todas as três palavras ocorrem, por exemplo, tanto em tragédia quanto em comédia), seu ethos, com seu escárnio desdenhoso de celebrações inúteis e de pobreza angustiante e pretensiosa, é fortemente reminiscente da Comédia Antiga.

Poderia Platão ter simplesmente inventado essas quatro citações do nada? Quase certamente não, pois sua linguagem é genuinamente poética, seus metros parecem autênticos e seria muito danoso para o argumento de Sócrates se ele tivesse de recorrer a citações falsificadas. Mas, mesmo que elas sejam citações poéticas genuínas, elas são desconcertantes em sua obscuridade, e não é provável que o véu dessa obscuridade seja completamente levando algum dia; qualquer proposta acerca de sua interpretação e colocação deve ser feita com cuidado enorme e com a consciência aguda de que outras compreensões, diferentes, não podem ser excluídas. Além disso, não há necessidade de que elas venham todas de um mesmo autor, ou gênero, ou período - com efeito, serviria melhor ao propósito retórico de Sócrates se acontecesse de elas derivarem de diferentes procedências. No entanto, a análise precedente dessas citações parece fazer uma atribuição de todas as quatro à Comédia Antiga no mínimo altamente plausível, se não absolutamente certa ${ }^{27}$. Metricamente, lexicalmente, estilisticamente, as duas primeiras bem poderiam ambas vir de canções monódicas ou corais, e as duas últimas de trímetros jâmbicos recitativos, todos eles escritos por Aristófanes ou por um ou mais de seus colegas e rivais ${ }^{28}$. Com efeito, nada há que nos impeça de supor que todas as quatro

\footnotetext{
${ }^{26}$ Adam (1965, vol. 2, p. 418) se lembra de Eurípides, mas as passagens que ele cita são de espírito muito diferente.

${ }^{27}$ Wilamowitz atribuiu todas as quatro citações a Sófron: veja-se Slings, 2003, p. 388. Mas o fato de que todas elas possam ser analisadas satisfatoriamente em termos de metros encontrados na Comédia Antiga torna improvável que elas tenham sido escritas por Sófron, que parece, até onde sei, ter composto sua obra em uma prosa rítmica.

${ }^{28}$ A sugestão de que a fonte de todas as quatro citações possa ser a Comédia não é nova. Adams (1965, vol. 2, p. 418), embora ele mesmo a conteste, a atribui a Ast, Prantl e Heine, entre os estudiosos mais antigos; e cf. mais recentemente e.g. Brock, 1990 , p. 40. Uma questão adicional é até que medida essa exata passagem em Platão - com seu agôn entre conceitos personificados e sua
} 
citações derivem não apenas no mesmo gênero, Comédia Antiga, mas também do mesmo autor e ainda do mesmo texto. Por tudo que sabemos, o que encontramos nessa passagem da República de Platão poderiam ser quatro fragmentos da primeira versão perdida das Nuvens de Aristófanes ${ }^{29}$.

Agora, alguns leitores bem poderiam pensar que nós já nos avançamos muito além do baixio do senso comum adentro das profundezas sombrias da especulação infundada. No entanto, essas últimas considerações sugerem uma questão mais, de modo tão tentador que é parece difícil resistir a ela. Afinal filólogos às vezes se precipitam onde anjos temem pisar. A questão é esta: para nós, as quatro citações de Platão são certamente fragmentos, na medida em que elas são remanescentes sobreviventes daquilo que foram uma vez textos inteiros, mas que não foram transmitidos como tais e estão provavelmente perdidos para sempre. Mas o que elas eram para os interlocutores ficcionais de Sócrates e, acima de tudo, para os verdadeiros leitores gregos antigos que o autor Platão tinha em mente? Eram elas fragmentos para eles também, no sentido de que essas citações continham seu sentido independentemente do conhecimento de seu contexto textual original, ou eram elas partes de todos que podiam ser trazidos à mente e que necessitavam ser trazidos à mente se elas haviam de ser inteiramente compreensíveis? Para afiar a questão: os leitores de Platão deviam reconhecer as citações e identificá-las como provenientes de um ou mais textos específicos, ou essas frases circulavam como expressões proverbiais desprovidas de qualquer contexto determinado?

Difícil como eram as questões anteriormente discutidas aqui, esta é incomparavelmente mais delicada. A favor da alternativa de que se esperava que essas frases fossem citações identificáveis num contexto lembrado é o fato de que pelo menos a primeira, uma metáfora ou símile, necessita de algum grau de contextualização, se sua referência aos filósofos há de ser reconhecível; mas, contra ela, fala a consideração de que a generalidade das afirmações de Platão e, talvez, também a longevidade da querela de que ele fala serão diminuídas se o leitor puder identificar todas as suas citações, especialmente se todas elas provierem exatamente da mesma fonte. A favor da

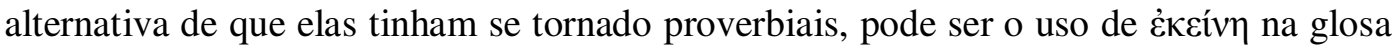
à primeira citação, onde $\dot{\eta}$ teria sido perfeitamente suficiente (o demonstrativo parece apontar não para algo que acabou de ser dito, mas para algo notório em si mesmo, independentemente da sua citação presente); mas, contra ela, fala o fato de que nenhuma das três frases jamais é citada como proverbial por escoliastas ou paremiógrafos antigos. Como havemos de decidir entre essas duas hipóteses rivais? Em termos abstratos, não temos dificuldade em distingui-las; mas eu não vejo qual indício possivelmente poderia decidir o assunto definitivamente para um lado ou para o outro. Minha própria preferência vai na direção da hipótese proverbial, uma vez que tomo mais seriamente a possível ameaça à força retórica da argumentação de Platão do que a ausência dessas frases do pouco que conhecemos acerca da erudição antiga. Mas eu preferiria, se possível, uma solução comprometedora, uma que se incline para essa opção, mas que não a abrace absolutamente, segundo a qual essas citações de fato circulavam por si mesmas, mas a maioria dos atenienses se lembrava de que elas vieram dos ataques da Comédia Antiga aos filósofos, mesmo se muitos deles já não tivessem mais certeza de que comédia ou comédias exatamente estavam envolvidas. Assim,

referência à "rudeza e falta de sofisticação" - poderia ser ela mesma colorida de algum modo pelas técnicas típicas da Comédia Antiga.

${ }^{29}$ Devo essa sugestão engenhosa a Dirk Obbink. 
também, muitas citações de Shakespeare circulam no discurso anglófono e são reconhecidas, no mínimo, por um certo número de falantes do inglês como derivadas de Shakespeare e possuidoras de algum tipo de referência determinada, mas somente muito poucos falantes podem seguramente identificar exatamente qual peça, muito menos a cena, de que elas vêm, e há muitas pessoas que usam essas frases competentemente, mas que não têm qualquer consciência de que elas derivam de Shakespeare. Minha suspeita é que o mesmo era verdade para as quatro passagens que Platão faz Sócrates citar; mas eu não vejo como isso possa ser provado.

Naveguemos de volta agora, da incerteza oceânica dos leitores de Platão para a segurança relativa do texto transmitido. Por um lado, identificar as citações como oriundas da Comédia Antiga pode parecer tornar muito mais fácil interpretar a enigmática referência de Sócrates à querela entre poesia e filosofia do que nós tínhamos pensado primeiramente. Pois, enquanto, como nós vimos, é de fato muito difícil encontrar qualquer traço de ataques a filósofos em qualquer outro gênero poético da literatura grega arcaica ou clássica, é bem sabido que a Comédia Antiga freqüentemente escolhia filósofos contemporâneos, assim como outros tipos de intelectuais, como alvo de sua invectiva: Anaxágoras, em particular, parece ter sido satirizado com freqüência, e temos nas Nuvens de Aristófanes uma comédia sobrevivente dedicada em grande parte a fazer Sócrates parecer ridículo. Mas, por outro lado, antes de saltarmos para a conclusão de que isso é o que Sócrates tem em sua mente e o que Platão deseja que seus leitores tenham nas suas, pelo menos dois problemas sérios com tal interpretação têm de ser apontados. Primeiro, Sócrates chama à querela palaia, "antiga", e, embora esse adjetivo não necessariamente denote algo perdido nas névoas da antiguidade primeva, ele certamente sugere algo suficientemente velho e suficientemente antigo para fornecer à discussão corrente uma dimensão temporal significante ${ }^{30}-\mathrm{e}$, no entanto, tais ataques cômicos a filósofos eram mais ou menos contemporâneos à data ficcional da República e, no máximo, a precedia em duas décadas. Por um lado, os estudiosos discordam acerca de quando exatamente se deve imaginar que as conversas da República aconteceram, e provavelmente não se pode propor uma só data que seja inteiramente isenta de anacronismo, mas todas as datas sugeridas variam de 425, a mais antiga, até 409/08, no mais tardar, como preferência pela parte inicial desse intervalo ${ }^{31}$; por outro lado, as Nuvens foram produzidas pela primeira vez para as Dionísias da cidade de 423, embora a versão que nós temos seja uma revisão não encenada de 418-16. Essa é uma diferença suficiente para justificar o termo palaia? E segundo, toda a estratégia retórica de Sócrates nesse ponto é destinada a despersonalizar sua querela com os poetas, a sugerir que ele não os está criticando simplesmente porque ele possui um rancor pessoal contra eles, mas está, ao contrário, encenando o que é apenas o mais recente episódio em uma disputa de longa data que mais envolve formas institucionalizadas de discurso do que meros indivíduos, e muitos anos de diferença em vez de uma rusga recente. Mas, se Sócrates cita apenas ataques da Comédia Antiga a filósofos a fim de reforçar sua causa, não corre ele o risco de nos lembrar do ataque de Aristófanes a ele nas Nuvens e, desse modo, dar a impressão de que ele não busca justiça imparcial para a filosofia, mas uma vendeta pessoal para si mesmo? Na Apologia de Platão, Sócrates afirma que o mal contra ele provocado pelas Nuvens de Aristófanes foi uma das principais razões da acusação contra ele (Apologia 18a-19c): essa discussão da poesia da República não será

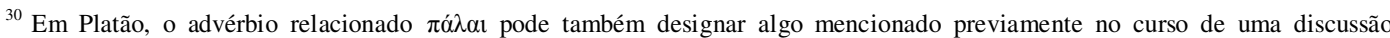
estendida, mas o advérbio geralmente, e o adjetivo sempre, aponta para algo que ocorreu bem antes do presente momento e está separado dele por tempo considerável: para uma compilação das passagens relevantes, veja-se Ast, 1835-38, vol. 3, 15-17.

${ }^{31}$ Doxografia em Erler, 2007, pp. 202-3.
} 
nada além da tentativa de Platão de vingar-se para conseguir alguma desforra para ele? Mas essa interpretação não parece pessoal demais, trivial demais para ser inteiramente plausível?

Esse é um assunto delicado e complexo, e eu duvido que possa ser resolvido com base exclusivamente nessa única passagem. Busquemos ajuda em outro lugar do corpus platônico. Há um outro texto platônico que nos fala de "uma antiga fábula" (palaios mythos) sobre os poetas:

\begin{abstract}
Há uma antiga fábula, legislador, que nós poetas nunca nos cansamos de contar que todos os leigos confirmam, acerca de que, quando um poeta se senta no tripé da Musa, ele não pode controlar seus pensamentos. Ele é como uma fonte onde a água pode jorrar sem controle. Sua arte é a arte da representação e, quando ele representa homens com características diferentes, ele não sabe qual dos discursos opostos contém a verdade. Mas, para o legislador, isso é impossível: ele não deve deixar que sua lei diga duas coisas diferentes acerca do mesmo assunto; sua regre tem de ser "um tópico, uma doutrina" (Leis IV, 719c) $)^{32}$.

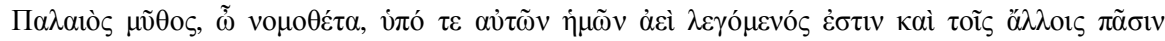

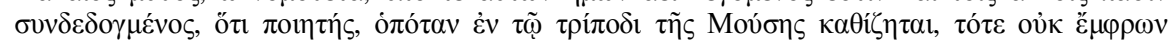

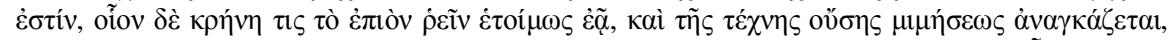

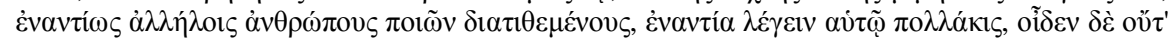

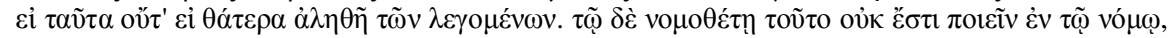

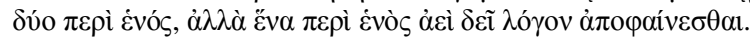

De acordo com o Ateniense, aqui, falando na voz do poeta, "uma antiga fábula" dizia que, quando os poetas compõem sob o efeito da inspiração divina, eles (a) estão fora de seu juízo, (b) representam mimeticamente outros personagens e, conseqüentemente, (c) acabam freqüentemente se contradizendo. Também aqui não há dúvida de que tais afirmações formam uma parte importante da doutrina do próprio Platão sobre a poesia. Mas também aqui a linguagem usada para transmiti-las certamente nos impele a perguntar simplesmente se realmente havia ou não havia uma tal "antiga fábula" imperante na cultura grega antes dos escritos do próprio Platão.

A resposta curta é, não, certamente não havia ${ }^{33}$. Sem dúvida, desde Homero os poetas gregos freqüentemente reivindicaram alguma forma de inspiração divina; mas, para a teoria unificada, complexa que Platão lhes atribui, falta qualquer indício. (a) No que concerne à inspiração poética, Hesíodo conta como as Musas lhe deram um ramo de louro e nele inspiraram a voz poética próximo de uma fonte, mas não diz absolutamente nada sobre estar fora de seu juízo (Teogonia, 22-35); Arquíloco diz que compõe poesia quando o vinho lhe tira a lucidez, mas nada diz sobre ditos oraculares ou Defos (fr. 120 West); Píndaro diz à Musa: "Dá-me um oráculo, Musa, e eu hei de ser teu profeta", mas não dá nenhuma indicação de ter perdido seu juízo (fr. 150 Sn.-M.). Se algumas das pequenas peças da "antiga fábula" do Ateniense acerca da inspiração poética podem assim ser encontradas espalhados nas declarações reais dos poetas gregos antigos, não há absolutamente nenhum indício coerente e substancial dessa visão no início da poesia grega; se ela há de ser encontrada em algum lugar antes de Platão, então provavelmente será apenas nas paródias dos poetas trágicos e ditirâmbicos nas comédias de Aristófanes e seus colegas. (b) Do mesmo modo, também no que diz respeito à mimesis de personagens, não há nada como a "antiga fábula" do Ateniense nos antigos mitos atestados da poesia grega. Diz-se, certamente, que Helena falou com as vozes das mulheres de diferentes guerreiros gregos enquanto eles se escondiam no cavalo de Tróia

\footnotetext{
${ }^{32}$ Sobre essa passagem, veja-se especialmente Schlesier (2006), cujas conclusões são próximas das minhas.

${ }^{33}$ Vejam-se, como exemplos em geral, Maehler (1963) e Ford (2002).
} 
(Homero, Odisséia 4. 274-79), e diz-se que as donzelas délias são capazes de imitar as vozes e os balbucios de toda a gente (Hino Homérico a Apolo 162-164), e diz-se que o monstro Tifeu imita os sons de todos os tipos de diversos animais e fenômenos naturais (Hesíodo, Teogonia 829-35) - mas em lugar algum há referência a um poeta arcaico imitando diferentes personagens e, de fato, é difícil imaginar que tal doutrina em algum momento tenha ocorrido a quem quer que seja antes das formas dramáticas de tragédia e comédia, nas quais os poetas faziam precisamente isso o tempo todo, terem não apenas sido inventadas, mas também terem se tornado, com o passar dos anos, um objeto familiar para reflexão. (c) E, finalmente, no que diz respeito à noção de poetas contradizendo-se, os poetas gregos arcaicos não hesitavam em contradizerem uns aos outros e sem dúvida se contradiziam a si mesmos de vez em quando; mas, dada a natureza largamente oral da poesia grega inicial, é provável que tais contradições dificilmente fossem notadas e criticadas, a menos que o próprio poeta escolhesse, por alguma razão, trazê-las à atenção de seus ouvintes, como, por exemplo, na autocorreção de Hesíodo concernente à genealogia de Éris (Os Trabalhos e os Dias 11-12) ou na celebrada Palinódia de Estesícoro a Helena (fr. 192-93 Page). Mas tais passagens certamente não garantem de modo algum que havia "uma antiga fábula" segundo a qual os poetas se contradiziam ao imitar diferentes tipos de pessoas.

Então, como é possível que o Ateniense possa afirmar, com uma plausibilidade mínima, que tal palaios mythos em algum momento existiu realmente? À idéia antiga real de inspiração poética, ele juntou uma série de consequiências e implicações que não são encontradas em lugar nenhum entre os poetas em que ele parece estar pensado, mas, se em algum lugar, então apenas nas paródias da Comédia Antiga de poetas que afirmam ser divinamente inspirados. Aqui, como noutros lugares, nossa tendência de traçar um limite estritamente genérico e histórico entre a comédia do século $5^{\circ}$ e a filosofia do século $4^{\circ}$ pode estar equivocada: Platão, para suas teorias literárias, parece ter aprendido com Aristófanes e seus colegas muito mais do que alguns estudiosos podem suspeitar.

Mas como o Ateniense pode safar-se de juntar essas outras noções à doutrina da inspiração poética como um palaios mythos único e amplamente partilhado? Talvez possamos ser tentados a tentar escapar desse dilema exegético, primeiro, sugerindo que alguém poderia interpretar mythos não como "fábula", mas meramente como "declaração", e tomar palaios em um sentido fraco, não como significando "antigo", mas meramente "de longa data, há um longo tempo" e, então, aplicando a frase não a algum mito ou fábula comum na cultura grega nos séculos anteriores a Platão, mas, em vez disso, às declarações do próprio Platão, voltando-se para a República e mesmo antes, para o Íon e outros textos iniciais, e agora repetidos e sumarizados pelo Ateniense. Afinal, não são todos os componentes desse palaios logos elementos familiares das doutrinas freqüentemente repetidas do próprio Platão? Mas esse caminho de fuga está completamente impedido para nós: pois não apenas mythos deve designar, se não um mito, alguma forma de declaração mais pública e mais institucional do que um modo de falar pessoal meramente ${ }^{34}$, e palaios deve indicar, aqui como na passagem da República X, uma distância temporal do presente significante, sem dúvida uma maior do que o período da carreira de um único autor; mas também, e acima de tudo, seria certamente uma forma muito bizarra de auto-referência, dado que o estranho

\footnotetext{
${ }^{34}$ Sobre o uso de Platão do termo mythos e o conceito de mito, veja-se mais recentemente Morgan (2000, p. 155-84) e Most (2002). A tradução de Cooper oferece aqui "provérbio", que captura esse aspecto público da palavra, mas enganosamente sugere uma sentença sucinta em vez de uma história complicada do tipo da que o Ateniense conta.
} 
Ateniense não é idêntico a Sócrates ou Platão e que essas palavras sequer são ditas em sua persona, mas naquelas de um poeta.

É sem dúvida melhor interpretar as palavras do Ateniense aqui como baseadas na interpretação filosófica de Platão daquilo que ele considerava ser o verdadeiro sentido dos mitos antigos sobre a inspiração divina dos poetas e outras figuras culturais carismáticas, e entender que elas derivam de tais mitos consequiências filosóficas (em grande parte inimagináveis para seus autores originais) à luz das doutrinas do próprio Platão acerca da technê, mimesis e outros temas relacionados. Isso significa dizer que, para Platão, as próprias noções de inspiração poética e mimesis devem necessariamente possuir certas características e colocar certos perigos, e para ele estes estão inevitavelmente contidos naquelas noções, de modo que, se elas não são explicitamente estabelecidas pelos poetas, elas podem legitimamente ser atribuídas a eles. Por exemplo, quando Hesíodo contava sua iniciação poética, ele seguramente não tinha em mente o sentido que Platão haveria de atribuir a ela três séculos depois; mas, do ponto de vista de Platão, essa sua interpretação filosófica é exatamente o que Hesíodo deve ter realmente querido dizer, um conjunto de idéias que bem podia não ser claro para ele quando ele compunha a sua Teogonia, mas que ele deveria ter reconhecido como seu significado verdadeiro, se Platão pudesse ter tido uma oportunidade de questioná-lo com obstinação suficiente. Afinal, Sócrates parece ter acreditado, pelo menos no testemunho de Platão, que ele seria capaz de conversar, no Mundo Inferior, com os mortos famosos, incluindo o próprio Hesíodo, depois de sua morte (Apologia 41a), e é difícil não imaginá-lo ávido para aproveitar essa oportunidade, para colocar exatamente tais questões.

Assim, num sentido, o Ateniense está completamente certo, pois o que está envolvido é, de fato, em algum sentido, uma antiga fábula; mas, ao mesmo tempo, ele apresenta essa antiga fábula sob a aparência de uma unidade perfeita, juntamente com uma interpretação completamente moderna e altamente idiossincrática que, de fato, atribui a ela um sentido que podemos reconhecer como muito diferente, mas cuja diferença ele elide completamente. Um tipo de alegorese filosófica que transporta a antiga declaração poética turva e difusa para a luz fria e clara do presente, onde ela pode revelar o que pode se dizer que ela realmente já significou sempre e pode fazer uma contribuição prestativa para a problemática moderna; ou, inversamente, a presente preocupação filosófica é retrojetada de volta ao passado distante onde se descobre que ela já era um componente essencial de uma tradição antiga e duradoura, uma tradição que jamais morreu - com efeito, uma tradição que foi levada a um vigor renovado no tempo de Platão e por meio de seus esforços. Nós, em nossa posição, podemos ver claramente que as antigas declarações poéticas estão sendo completamente transformadas em seu sentido pelo discurso platônico, de modo que elas podem vir a significar algo muito diferente daquilo que os poetas mesmos devem ter querido dizer; mas, para o alegorista filosófico, essa diferença, que nós não podemos deixar de reconhecer, é inteiramente irreal ou, pelo menos, invisível para ele, pois ele está totalmente convencido de que aquilo que eles queriam dizer é exatamente o mesmo que aquilo que ele diz agora que eles queriam dizer.

Para retornar à passagem da República X de onde nós começamos: com certeza, é obvio que há algumas diferenças significativas entre esse texto e o das Leis IV. Pois este se vale astutamente da ambigüidade na palavra mythos (uma fábula antiga exatamente como os poetas a contavam ou seu verdadeiro sentido como o filósofo o explica agora?) e alegoriza passagens que ele não cita, ao passo que o primeiro é 
reforçado por citações que são certamente genuínas e não as submete a uma interpretação alegórica. Mas, no entanto, colocar essas duas passagens juntas pode nos ajudar em nossas dificuldades iniciais de entender o qual o significado da "antiga querela entre poesia e filosofia". Pois fazer isso sugere que, em certo sentido, simplesmente não havia tal coisa. Em ambas as passagens, Platão faz generalizações tão amplas a partir dos indícios da poesia, que chega muito próximo da completa invenção - sem, no entanto, chegar lá totalmente. Platão não é um historiador da literatura: ele não é uma testemunha confiável da tradição real que existia antes e independentemente dele, que ele agora traz à nossa atenção como um fato neutro digno de ser relembrado. Em vez disso, em certo sentido, ele na verdade inventou essa tradição por um processo que envolve dois passos: ele cita declarações poéticas como fragmentos anônimos, desse modo isolando-as e descontextualizando-as; e ele as generaliza de tal modo que elas podem se tornar indício não apenas de personalidades individuais, mas de estruturas discursivas maiores. Um sinal desse procedimento de generalização é que Platão faz Sócrates falar não apenas de determinados filósofos e poetas individuais nessa passagem, mas de philosophia, filosofia, e poiêtikê, poesia; outro é que ele usa o mais vago de todos os termos possíveis para denotar a diferença entre elas, nomeadamente diaphora e enantiôsis, em vez de algo mais específico e mais pessoal; um terceiro é que ele amplia o horizonte temporal ao chamar à querela palaia, desse modo estendendo-a para o passado, do presente momento de inconfortável proximidade com as Nuvens de Aristófanes para horizonte passado mais vago, mais difuso, mais impessoal e, portanto, retoricamente mais seguro; e um quarto é que ele adiciona, depois dessas quatro citações, para o caso de elas não serem suficientes, que há muitas, muitas outras que ele também poderia citar, se ele resolvesse. Esse mesmo procedimento, aliado à tendência de descontextualizar a citação, leva Platão a fazer Sócrates não identificar nem o autor nem o gênero de nenhuma das passagens que ele cita (pois indicar sua exata procedência estreitaria o escopo de suas afirmações e, desse modo, tenderia a deslegitimá-las). De fato, as únicas querelas relevantes que têm algum papel substancial na história literária grega no período até Sócrates não opõem filosofia tout court a poesia tout court, mas Xenófanes às descrições tradicionais dos deuses encontradas inter alia nos poetas épicos, e não poesia tout court a filosofia tout court, mas sim Comédia Antiga aos movimentos intelectuais genéricos que chamamos filosofia e Sofística, e em termos mais precisos contrapõem primeiro alguns dramaturgos cômicos a Anaxágoras e, então, um pouco depois, Aristófanes em particular a Sócrates - mais uma razão por que Platão bem poderia ter preferido não fazer Sócrates identificar mais exatamente as fontes de suas citações. E estas não são realmente oposições genéricas entre filosofia e poesia tout court, de qualquer forma, mesmo porque há pouca ou nenhuma evidência de qualquer consciência de tal oposição genérica antes de Platão e essa oposição pode mesmo estar no processo de ser construída nesse exato texto dele.

A partir dessa estreita e, potencialmente, desconfortável base pessoal, Platão constrói um grande e fundamental conflito de valor cultural e filosófico ao estender substancialmente e supergeneralizar radicalmente um caso único ou grupo de casos fortemente conectados. Isso significa que Platão simplesmente inventou a antiga querela? Sim, mas apenas em um certo sentido. Dizer que a querela é em grande parte um conseqüência do modo como Platão via a poesia e a filosofia anteriores e contemporâneas não significa que ele conscientemente a fabricou, que ele reconheceu que ela estava impondo significados aos escritores anteriores que eram historicamente 
falsos, que ele tentava enganar seus leitores conferindo à filosofia um status ao qual ela não estava autoriza, ou que ele intencionalmente falsificava uma disputa não existente para seus próprios propósitos retóricos. Em vez disso, dados os compromissos filosóficos de Platão, era inevitável que ele lesse os filósofos anteriores dessa maneira, atribuindo-lhes o significado que ele seguramente estava convencido de que eles deviam ter tido em mente - ou teriam tido, se ele pudesse ter-lhes perguntado.

Visto sob essa luz, torna-se evidente que há uma diferença significativa entre o que Platão queria dizer com "a antiga querela da poesia e filosofia" e o que alguns estudiosos recentes quiseram dizer com a mesma frase: os estudiosos que retrojetaram as palavras de Platão às condições anteriores da literatura grega parecem estar pressupondo que ele lia exatamente como nós o fazemos, e negligenciando a diferença entre, por um lado, seu modo de ler, seus interesses e seu programa, e, por outro, os nossos. Essa diferença não é nada mais, mas também nada menos, do que a diferença entre a filosofia antiga e a história moderna da literatura. E essa diferença, contrariamente à "antiga querela da poesia e filosofia", é uma diaphora ou enantiôsis bastante real ${ }^{35}$.

\section{BIBLIOGRAFIA}

ADAM, James. The Republic of Plato. 2 volumes. D.A Ress, 1965 (1 ${ }^{\mathrm{a}}$ edição: Cambridge: Cambridge University Press, 1902).

ASMIS, Elisabeth. Plato on Poetic creativity. In: KRAUT, R. (org.). The Cambridge Companion to Plato. Cambridge: Cambridge University Press, 1992.

AST, Friedrich. Lexicon Platonicum. 3 volumes. Leipzig: Libraria Weidmanniana, 1835-38.

BROCK, Roger. Plato and Comedy. In: Craik, E. (org.). Owls to Athens: essays on Classical Subjects Presented to Sir Kenneth Dover. Oxford: Oxford University Press, 1990.

COOPER, John. Plato, Complete Works. Indianapolis: Hackett Publishing Company, 1997.

ERLER, Michael. Platon. Grundriss der Geschichte der Philosophie. Die Philosophie der Antike, Bd. 2/2. Basel: Schwabe Verlag, 2007.

FERRARI, G. R. Plato and Poetry. In: KENNEDY, G (org.). The Cambridge History of Literary Criticism, v. 1. Classical Criticism. Cambridge: Cambridge University Press 1989.

FORD, Andrew. The Origins of Criticism. Literary Culture and Poetic Theory in Classical Greece. Princeton: Princeton University Press, 2002.

GOULD, Thomas. The Ancient Quarrel between Poetry and Philosophy. Princeton: Princeton University Press, 1990

KANNICHT, Richard. Paradeigmata. Aufsätze zur griechischen Poesie. Heidelberg: Universitatsverlag C. Winter, 1996.

LEVIN, Susan. The Ancient Quarrel between Philosophy and Poetry Revisited. Oxford: Oxford University Press, 2001.

MAEHLER, Herwig. 1963. Die Auffassung des Dichterberufs im frü hen Griechentum bis zur Zeit Pindars. Göttingen: Vandenhoeck and Ruprecht, 1963.

\footnotetext{
${ }^{35}$ Traduzido por José Baracat Jr.
} 
MORGAN, Kathryn. Myth and Philosophy from the Presocratics to Plato. Cambridge: Cambridge University Press, 2000.

MOSS, Jessica. What is Imitative Poetry and Why is it Bad? In: FERRARI, G (org.). The Cambridge Companion to Plato's Republic. Cambridge: Cambridge University Press, 2007.

MOST, Glenn W. The Poetics of Early Greek Philosophy. In: LONG, A. (org.). The Cambridge Companion to Early Greek Philosophy. Cambridge: Cambridge University Press, 1999.

. Pindars Sonnenfinsternis: A Total Eclipse of the Heart. In: M. BAUMBACH, M. et alii (orgs.). "Stürmend auf finsterem Pfad..." Ein Symposion zur Sonnenfinsternis in der Antike. Heidelberg: Winter Verlag, 2000.

MURDOCH, Iris. The Fire and the Sun: Why Plato Banished the Artists. Oxford: Oxford University Press, 1977.

MURRAY, Penelope. Plato on Poetry. Cambridge: Cambridge University Press, 1996.

NADDAFF, Ramona. Exiling the Poets. Chicago: Chicago University Press, 2002.

NIGHTINGALE, AndreaW. Genres in Dialogue: Plato and the Construct of Philosophy. Cambridge: Cambridge University Press, 1995.

PARKER, L. P. E. The Songs of Aristophanes. Oxford: Clarendon Press, 1997.

ROSEN, Stanley. The Quarrel between Philosophy and Poetry: Studies in Ancient Thought. London: Routledge, 1988.

SCHLESIER, Renate. Schlesier, Platons Erfindung des wahnsinnigen Dichters. Ektasis und Enthusiasmos als poetisch-religiöse Erfahrung. Zeitschrift für Ästhetik und Allgemeine Kunstwissenschaft, 52, p. 45-60, 2006.

SLINGS, Simon R. Platonis Politeia. Oxford: Oxford University Press, 2003. 